\title{
On morphology, molecular composition and breakdown behaviour in semi-crystalline polymers
}

\author{
C. P. Martin ${ }^{1}$, A. S. Vaughan ${ }^{1}$, and S. J. Sutton ${ }^{2}$ \\ ${ }^{1}$ University of Southampton, Southampton, UK \\ ${ }^{2}$ National Grid, Coventry, UK
}

\begin{abstract}
The short-term dielectric breakdown behaviour of a number of model polymer systems has been investigated. For polyethylene blends, it is found that the addition of linear polyethylene and the imposed thermal history of the blend have, jointly, resulted in a significant improvement in properties. The effect of anti-oxidants and DCP on the breakdown behaviour of LDPE and XLPE is discussed; these have a negligible effect. Finally, for a clarified propylene/ethylene copolymer, it is found that crystallization conditions have a significant effect on electrical strength although the effect of the clarifying additive alone is less certain.
\end{abstract}

\section{Introduction}

Several studies have been performed in which the influence of morphology, composition and additives on the short-term breakdown behaviour of semi-crystalline polymers has been examined [1-4].

In this paper, we will describe a number of related investigations in this area, in which a range of model systems have been designed in order to explore certain aspects of breakdown behaviour. The specific objectives of this work are:

i) To explore the effect of composition and blending route for polyethylene blend systems.

ii) To discuss the effect of antioxidant additives and crosslinking by-products on the morphology of low density and crosslinked polyethylene with respect to their influence on breakdown behaviour.

iii) To investigate the effect of a nucleating additive on the morphology and breakdown behaviour of a propylene/ethylene copolymer. Such materials possess high optical clarity and are considered to be good model systems for studies of electrical tree growth [4].

\section{Experimental}

The work described here concerns a number of model semicrystalline polymer systems. Polyethylene blends of high density polyethylene (HDPE) Rigidex 140/60 (BP) and low density polyethylene (LDPE) 4901 (Borealis) were prepared and compared with the LDPE alone. In the blend, the morphology was adjusted by varying the molecular composition and thermal history of the material; here, the quenched LDPE is compared with only one blend containing $20 \%$ HDPE, which was crystallized at $115{ }^{\circ} \mathrm{C}$. The effect of small molecular additives was then studied using a single Borealis low density polyethylene (LDPE), in three forms: virgin polymer (Material A); polymer plus antioxidant (Material B) and polymer plus antioxidant plus dicumyl peroxide (DCP) (Material C). Finally, two propylene/ ethylene copolymer systems, containing approximately $3 \%$ ethylene [4], were compared. These materials were produced by BASF and are termed Novolen 3240NC and Novolen 3200MC. Both are based upon the same polymer but the latter is modified by the addition of 2000 ppm of a sorbitol-based clarifying agent.

For morphological analysis, samples were etched in solutions of potassium permanganate in a mixture of phosphoric and sulphuric acid. Standard replication techniques [1] were employed to generate replicas for transmission electron microscopy (TEM); for scanning electron microscopy (SEM), the etched surfaces were merely sputter coated with gold.

A Grasby-Specac hydraulic press was used to produce polymer film samples of known thickness (typically $70 \mu \mathrm{m}$ ) for electrical testing. A standard electrical ramp test procedure was performed on each batch of samples (one batch being of the same material, crystallization conditions and sample thickness). Each film was immersed in Dow Corning silicone oil and placed between vertically opposing $6.3 \mathrm{~mm}$ diameter ball bearing electrodes. The voltage was increased at, typically, 50V/s until the sample failed. This test procedure is in line with the ASTM standard D149-87.

\section{Results}

\section{Polyethylene blends}

Figure 1 compares the morphology of the quenched LDPE with that present in the blend (i.e. 20\% HDPE blend crystallized at $115^{\circ} \mathrm{C}$ ). From Fig. 1a, the LDPE can be seen to consist of a continuous banded spherulitic texture, composed of many fine lamellar crystals. The blend sample exhibits a similar morphology (see Fig. 1b) but, in this system, all textural dimensions are significantly increased. Initially, the HDPE crystallizes to form a framework of extensive lamellae, surrounded by molten LDPE, which serves to 

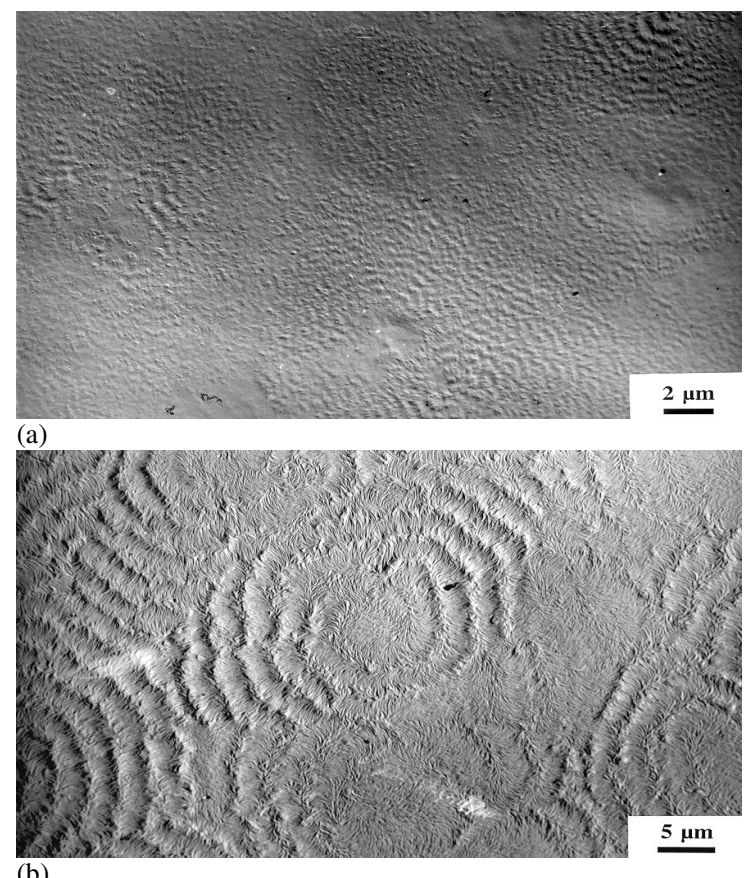

(b)

Figure 1: TEM images comparing the morphology of the two polyethylene systems; (a) LDPE, (b) a blend containing 20\% HDPE, which was crystallized at $115^{\circ} \mathrm{C}$.

retain impurities "in solution", such that they do not become concentrated at particular locations. Defect-rich sites are the likely origin of the association of spherulitic development with reduced breakdown strength [5]. The LDPE then crystallizes upon quenching, such that the resultant morphology contains spherulites but does not contain weak inter-spherulitic boundaries.

The short term breakdown behaviour of the blend was then compared with that of the quenched LDPE and the results were analyzed both in terms of typical Weibull [6] plots and by calculating mean breakdown strengths. Since the method of data analysis did not affect our conclusions, mean values will subsequently be quoted. Mean breakdown strengths for the LDPE and the blend are $130.7 \pm 5 \mathrm{kV} / \mathrm{mm}$ and $149.9 \pm 2 \mathrm{kV} / \mathrm{mm}$ respectively.

From the above data, it is evident that the addition of 20\% HDPE coupled with controlled crystallization, can increase the breakdown strength of polyethylene. This conclusion did not depend upon the sample thickness or the experimental procedure used to obtain the breakdown data. Also, it did not depend upon the method of blend production (melt mixing or solution blending), although this did dramatically affect the spherulitic dimensions. Thus, any additives that are removed by dissolution have a negligible impact upon breakdown, as does contamination introduced by melt

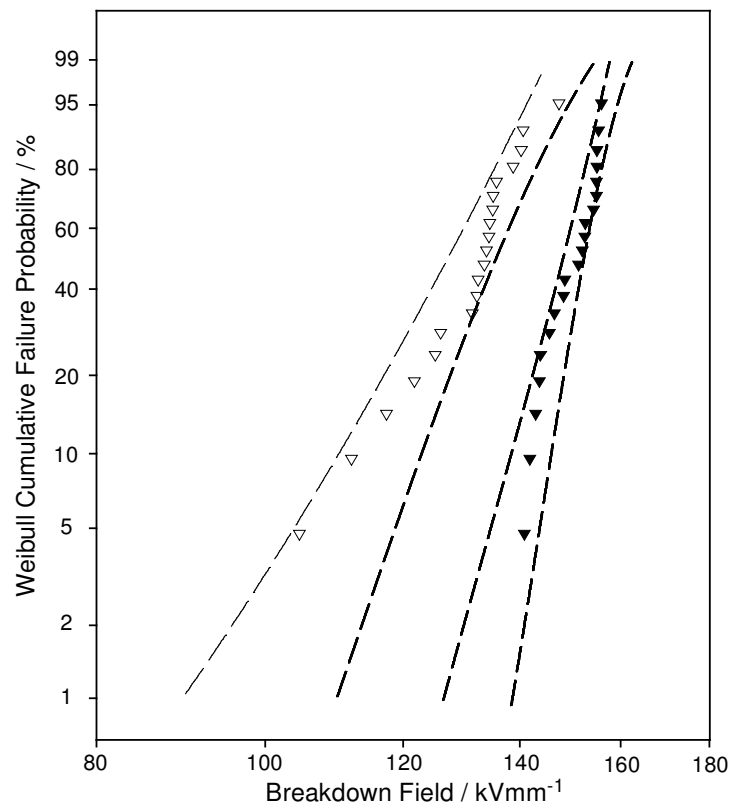

Figure 2: Weibull plots comparing the breakdown behaviour of the base LDPE $(\nabla)\left(E_{o}=135 \pm 3 \mathrm{kV} / \mathrm{mm}\right)$ with that of the blend ( $)\left(E_{o}=152 \pm 2 \mathrm{kV} / \mathrm{mm}\right)$.

mixing. Although spherulte size depends upon blending route, the local lamellar texture does not. Since the enhanced electrical strength of the blend is independent of blending method, the ultimate failure process is associated with the local lamellar structure, rather than the gross spherulitic texture. Practically, extrusion, as used in cable manufacture, results in massive nucleation which prohibits the formation of spherulitic structures.

\section{Additives and LDPE}

In the above study, the polymeric composition was varied by blending while, here, a single polymer was used, but with different small molecular additives, as above, morphological changes were also considered with respect to each material's breakdown response.

In the absence of any additives, spherulitic structures develop in the virgin polyethylene at low temperatures $\left(102{ }^{\circ} \mathrm{C}\right.$ and below), which have much in common with the morphology shown in Fig. 1. Figure 3 illustrates the range of alternative forms in this material, by reference to Material B. At low temperatures, addition of the antioxidant has induced massive nucleation (Fig. 3a), such that no evidence of spherulitic organisation remains. However, at the lamellar scale, crystallization proceeds in a similar manner to the virgin polymer. While the presence of the DCP itself has little effect on morphology, heating the system to $200{ }^{\circ} \mathrm{C}$ to 


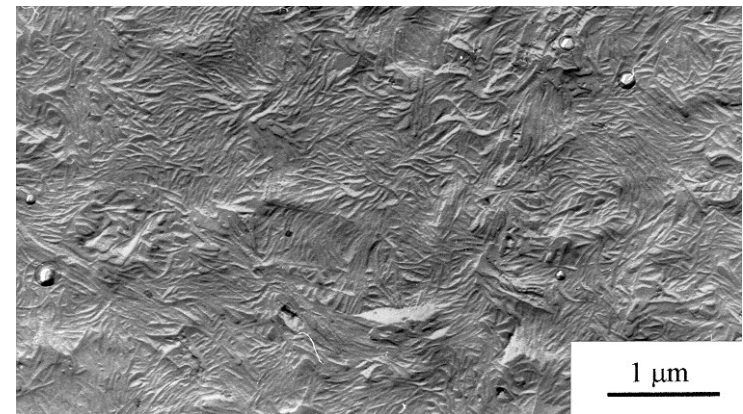

(a)

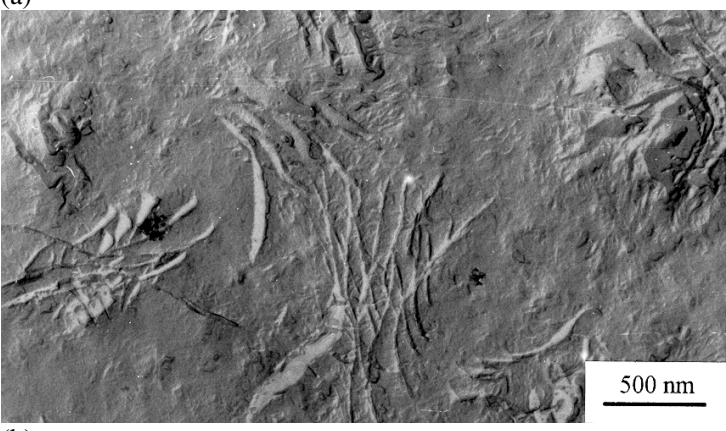

(b)

Figure 3: TEM images of Material B; (a), a space-filling lamellar texture after crystallization at $102{ }^{\circ} \mathrm{C}$ and (b), many small lamellar aggregates after crystallization at $108^{\circ} \mathrm{C}$.

induce crosslinking prior to crystallization impedes the crystallization process, as determined by thermal techniques. Nevertheless, similar lamellar textures to Fig. 3a still develop. At higher temperatures, the rate of crystallization is dramatically reduced, such that only a few isothermal crysalline objects form, which are surrounded by a quenched matrix, as shown in Fig. 3b.

From Fig. 1a and Fig. 3, it is evident that a wide range of different supermolecular structures can develop within this polymer. However, the lamellar texture does not vary greatly and, consequently, these samples have much in common with the study described above, in which changing the processing route suppressed spherulitic dimensions but did not affect the local lamellar texture. The breakdown strength of each of the above systems was then measured and the whole data set was analysed using a standard statistical $t$-test [7], to test the null hypothesis that the individual data sets that make up Fig. 4 do not differ significantly from the global mean (the mean plus uncertainties are indicated by the horizontal lines in Fig. 4). Although, using statistical criteria alone, it would appear that variations do exist, when structural factors are considered alongside the statistics, no clear trends emerged to indicate that either the compositional or morphological variations were reflected in the short-term electrical failure processes.

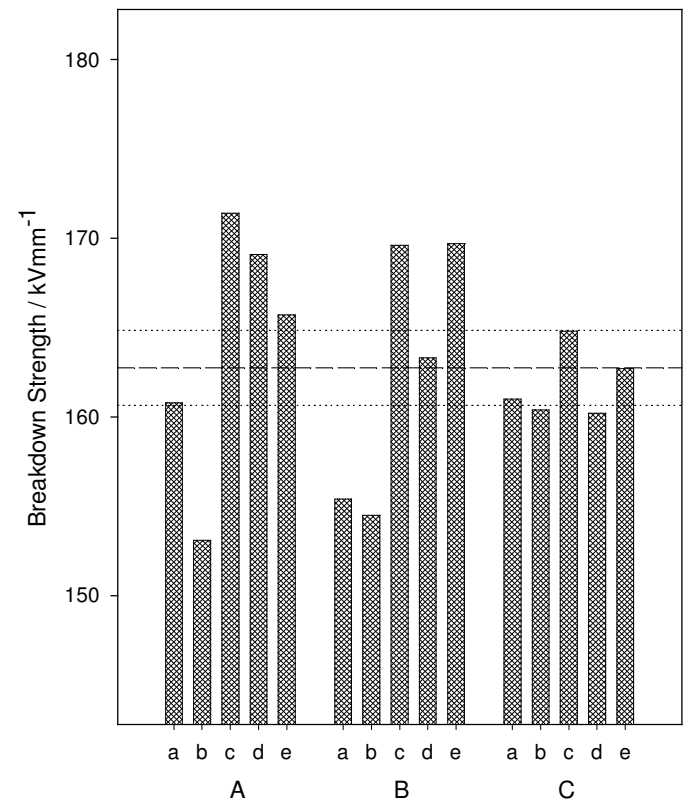

Figure 4: Breakdown data for samples of Materials A, B and C as a function of thermal history - a: quenching from $150{ }^{\circ} \mathrm{C}, \mathrm{b}$ : quenching from $200{ }^{\circ} \mathrm{C}$, c: isothermal crystallization at $102{ }^{\circ} \mathrm{C}$ following melting at $150{ }^{\circ} \mathrm{C}$, d: isothermal crystallization at 108 ${ }^{\circ} \mathrm{C}$ following melting at $150{ }^{\circ} \mathrm{C}$, e: isothermal crystallization at $102{ }^{\circ} \mathrm{C}$ following melting at $200{ }^{\circ} \mathrm{C}$.

\section{Novolen 3200MC and 3240NC}

Figure 5 compares the morphology of unclarified Novolen following quenching (Fig. 5a) or isothermal crystallization at $134^{\circ} \mathrm{C}$ (Fig. 5b). The latter sample was self-seeded [8] at $162{ }^{\circ} \mathrm{C}$, prior to crystallization. Samples of clarified material were also prepared via quenching or crystallization at the same temperature but were not subject to any form of self-seeding.

In Fig. 5a, spherulitic structures are clearly visible while in Fig. 5b there is no evidence for this. Instead, one can see extended structures based on quadrites. Previous studies [4,9] have shown that nucleation density is greatly enhanced by the presence of the clarifying agent, resulting in a continuous microstructure. However, the morphology of the clarified material was observed to resemble that shown in Fig. 5b when crystallized at $128{ }^{\circ} \mathrm{C}$ and above, despite the nucleation density remaining constant.

In this study, quenched batches of clarified and unclarified Novolen were found to possess identical mean breakdown strengths of $163 \pm 6 \mathrm{kV} / \mathrm{mm}$, while crystallized clarified and unclarified samples possessed values of $143 \pm 8 \mathrm{kV} / \mathrm{mm}$, which is in close agreement with previous findings [4] and $162 \pm 11 \mathrm{kV} / \mathrm{mm}$ respectively. The electrical strength values of the two batches of unclarified Novolen are apparently identical despite significant morphological differences. However, 


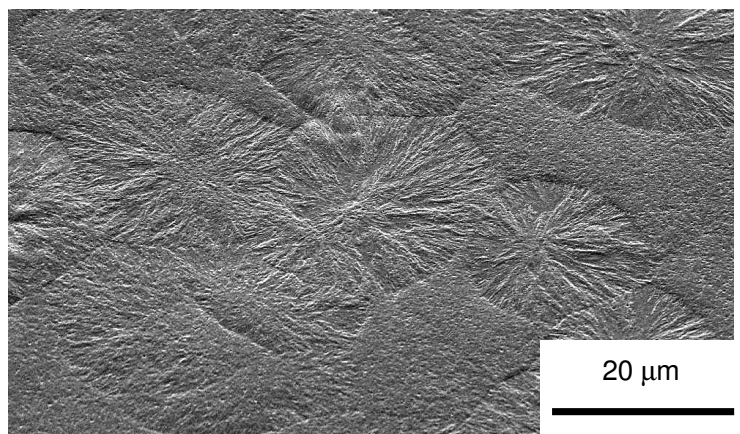

(a)

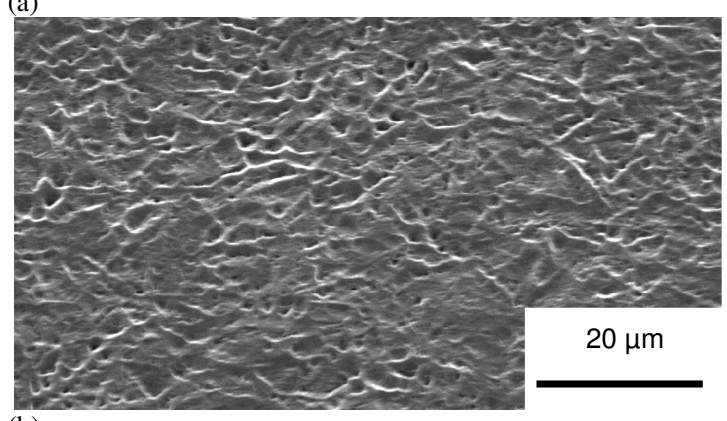

(b)

Figure 5: SEM images of Novolen 3240NC; (a) spherulitic structures that form upon quenching and (b) extended structures that form during crystallization at $134{ }^{\circ} \mathrm{C}$.

increased scatter in the final data set, which is reflected in the relatively large uncertainty $( \pm 11 \mathrm{kV} / \mathrm{mm})$ does mean that it is difficult to draw any definitive conclusions. This sample was the only one of the four that was subjected to the self-seeding procedure (to induce nucleation). We are not aware of any other work where the effect of self-seeding on breakdown behaviour has been considered.

\section{Conclusions}

The short-term dielectric breakdown behaviour of several model systems has been investigated. The initial study produced two conclusions. First, that enhanced properties can result from modifying the local lamellar texture through blending and, second, by necessity, that our testing procedure can discriminate between different systems. However, to achieve the required morphology of extensive, thick lamellae, relatively large changes were needed in both molecular composition (20\% HDPE here) and thermal history (high temperature crystallization). In the second study, the effect of a technologically relevant series of additives was considered. In these materials, two factors could, potentially, have influenced breakdown behaviour; the additives could exert a direct effect or, alternatively, they could influence breakdown indirectly, through their effect on the base polymer's morphology. Neither effect could be identified clearly and, therefore, our best interpretation of the results is that such additives, either directly or indirectly, only exert a minor influence. Although significant changes in spherulitic structure were seen, all materials contained only small lamellar crystals. The final study was undertaken in an attempt to explore further, the influence of additives and thermal processing on morphology and breakdown behaviour. Again, although significant morphological changes were observed, the changes in breakdown behaviour were far from clear.

\section{Acknowledgements}

The authors acknowledge the support of The National Grid Co. plc and their permission to publish this work.

\section{References}

[1] I. L. Hosier, A. S. Vaughan and S. G. Swingler, "On the Effects of Measuring Technique and Sample Preparation On The Breakdown Strength of Polyethylene", IEEE Trans. Diel. Electr. Insul, vol. 9, pp. 353-361, Jun. 2002.

[2] I. L. Hosier, A. S. Vaughan and S. G. Swingler, "The Effects of Morphology and Molecular Composition on the Electrical Strength of Polyethylene Blends", J. Polym. Sci Part B: Polym. Phys, vol.. 38, pp.2309-2322, Sept. 2000.

[3] A. S. Vaughan, Y. Zhao, L. L. Barré, S. J. Sutton and S. G. Swingler, "On Additives, Morphological Evolution and Dielectric Breakdown in low Density Polyethylene", Eur. Polym $J$, vol. 39, pp 355-365, Feb. 2003.

[4] Y. Zhao, A .S. Vaughan, S. J. Sutton and S. G. Swingler, "On the Crystallization, Morphology and Physical Properties of a Clarified Propylene/Ethylene Copolymer", Polymer, vol. 42 pp 6587-6597, Jul. 2001.

[5] S. N. Kolesov, "The Influence of Morphology on the Electric Strength of Polymer Insulation", IEEE Trans. Electr. Insul., Vol. 15, pp. 382-388, Oct. 1980.

[6] M. Cacciari, G. Mazzatani and G. C. Montanari, "Weibull Statistics in Short-term Dielectric Breakdown of Thin Polyethylene Films", IEEE Trans. Diel. Electr. Insul., vol. 1, pp. 153-159, Feb. 1994.

[7] R. J. Barlow, Statistics, Chichester UK: John Wiley 1989.

[8] Y. Zhao, A. S. Vaughan, S. J. Sutton and S.G Swingler, "On Nucleation and the Evolution of Morphology in a Propylene/Ethylene Copolymer", Polymer, vol 42 pp 6599-6608, Jul. 2001

[9] C. P. Martin, A. S. Vaughan, S. J. Sutton and S. G. Swingler, "Crystallization Behaviour of a Propylene/Ethylene Copolymer: Nucleation and a Clarifying Additive", J. Polym. Sci. Part B: Polym. Phys, vol 40, pp 2178-2189, Oct. 2002.

Author address: Christopher P. Martin, ECS, Faraday Building, University of Southampton, Southampton SO17 1BJ, UK, Email: cpm00r@ecs.soton.ac.uk 